\title{
Sôbre Dipteropeltis hirundo Calman, Crustáceo (Branchiura) parasito de peixes dágua doce
}

\author{
João de Paiva Carvalho
}

Estagiário voluntário

(Estampas XIX e XX)

Em julho de 1940, recebi alguns Crustáceos parasíticos de peixes dágua doce, remetidos pelo Snr. Ary Freire, fiscal de Caça e Pesca, residente na cidade de Boa Esperança, no Estado de São Paulo. Ésses ecto-parasitos provinham do ribeirão Boa Esperança e do rio Jacaré-guassú, tendo chegado às minhas mãos em ótimas condições de conservação, dado o cuidado com que foi feita a sua coleta, pelo exímio pescador amador, Snr. Bento Ahern, Cirurgião-Dentista, residente na citada localidade.

Encontrei no material um Branchiuro, pertencente ao gênero $D i p t e r o-$ peltis Calman 1912, descrito, no ano seguinte, com o nome de Tala us por Moreira (1913). Segundo informações dos colecionadores, que declararam ser o hospedeiro um lambarí do rabo vermelho, acredito tratar-se de Te tragonopterus rutilus, espécie muito espalhada pelos cursos fluviais do Interior do Estado de São Paulo.

Como os caracteres do primeiro exemplar do Branchiuro mencionado no título do trabalho presente me pareceram divergir tanto da espécie de Calman, quanto da de Moreira, deliberei fazer novas tentativas para conseguir mais material, afim de poder julgar a espécie na base dum número maior de especimes.

Com êsse objetivo realizei, em Setembro de 1940, uma excursão peic município de Boa Esperança, durante a qual tive ocasião de examinar 95 lambarís do rabo amarelo, Tetragonopterus aureus, 5 piquíras. Characidium fasciatum, 8 canivetes, Parodon affinis, 3 
piapáras, Leporinus sp., e um pequeno bagre de cabeça chata do gênero Trichomycterus. Encontrei, porém, somente dois Isopoda da família Cymothoidae e, como único Branchiuro, Dolops I ongicauda Heller.

No mez de Janeiro de 1941, o mesmo Snr. Ary Freire me remeteu mais material para estudo, no qual encontrei dois representantes do gênero $D$ i p teropeltis, ambos fêmeas, que haviam sido retiradas das nadadeiras peitorais de lambarís do rabo vermelho, tambêm conhecidos pelo nome vulgar de tambiú. O primeiro espécime foi capturado em data de 10-12-1940 e - outro em 8-1-1941. Os hospedadores provinham do ribeirão Boa Esperança. Ainda em fins de Fevereiro do mesmo ano, recebi, da mesma proveniência e de idêntico hospedeiro, mais uma fêmea capturada em 3-2-1941.

Os exemplares de Calman (1912) e de Moreira (1913; 1913a) foram colhidos em Corumbá e Cáceres, no rio Paraguai, onde parasitaram o dourado ( $S$ a I minus spec.) e a piranha (Pygocentrus piraya) respetivamente. Provindo o material ulterior de Moreira (1915) igualmente do Estado do Mato Grosso, alarga-se, pelo achado atual no Estado de São Paulo, - quadro da distribuição do gênero Dipteropeltis. Como, porém, o ribeirão Boa Esperança pertence ao sistema fluvial do Paraná, evidencia-se, sem delongas, a ligação hidrográfica.

Mais dificil parece estabelecer a união morfológica, visto tal não se seguir imediatamente das diagnoses anteriores. Originalmente tinha Moreira $(1913$, p. 147; 1913a, p. 9) caracterizado sua espécie pela ausência de antenas. Somente mais tarde (1915), com novo material, verificou a presença das antênulas ( 1 as $^{\text {as }}$ antenas) e antenas (2. as antenas). No último trabalho subordinou (p. 120) o gênero Talaus como sinônimo, a Dipteropeltis. Essa publicação escapou, evidentemente à atenção de Wilson (1932), que continua (p. 539) a mencionar separadamente Dipteropeltis Calman, com antenas e Talaus, sem antenas. O novo "Nomenclator Zoologicus" (Neave 1939-1940) indica corretamente a sinonimia, como foi estabelecida pelo próprio autor do gênero Tal a us. Seja mencionado, de passagem, que o nome Tala us, pre-ocupado em 1886 pelo arachnólogo E. Simon, foi substituido por Moreiriella (Mello-Leitão 1913; veja Moreira 1915), caindo êste último nome naturalmente tambêm na sinonimia de Dipteropeltis Calman 1912.

Ao abandonar o nome genérico de Tala us, Moreira (1915) aceitou tambêm o nome específico dado por Calman. Não tenho dúvida de classificar o material aqui em mãos igualmente como Dipteropeltis hiru ndo Calm., apesar de precisarem as descrições dos dois autores precedentes de certas emendas. Não concordam, p. e., as antênulas e antenas, como foram desenhadas por Calman $(1912$, f. 3), com os apênudices corres- 
pondentes do material atual, em que se aproximam mais à figura de Moreira, embora êste último tambêm não os tenha representado exatamente. Faltam, na ilustração de Moreira, as porções basilares de aspeto globoso (Fig. 4). descritas corretamente por Calman.

Quanto ao estilete pre-oral sumariou Wilson (1932, p. 539) demais as observações da diagnose original, dizendo: dois pares de antenas rudimentares e um estilete pre-oral. Calman notou, porém, no seu material apenas - elemento correspondente à bainha do estilete pre-oral, conhecido de Argulus, e afirma não ter visto, nem mesmo vestígio do próprio estilete ou pico, nos dois exemplares dissecados. Ao resumir os caracteres genéricos de Dipteropeltis realça Calman novamente: papilas pre-orais presentes, mas nenhum estilete.

$\mathrm{Na}$ descrição dos discos adesivos, dada por Calman, encontra-se a passagem seguinte: em lugar dos suportes radiais comuns são todos os bordos membranosos da ventosa cobertos por escamas idiscoidais. As preparações por mim efetuadas revelaram, porém, a existência de çostelas de sustentação do exosqueleto quitínico, semelhante quasi às presentes nas espécies de Argulus, porém dispostas horizontalmente, em duas camadas paralelas, como mostra a Figura 5 (est. XX).

Os pormenores mencionados, assim como outros que se depreendem da diagnose seguinte, evidenciaram a necessidade da apresentação duma nova descrição do Branchiuro em questão.

\title{
Dipteropeltis hirundo Calman
}

\author{
Dipteropeltis hirundo Calman, 1912, p. 763, t. 84. \\ Talaus ribeiroi Moreira, 1913, p. 147, t. 4, f. 4-6. \\ Talaus ribeiroi Moreira, 1913a, p. 9, t. 3-4. \\ Dipteropeltis hirundo Moreira, 1915, p. 120.
}

Material: 4 exemplares, todos fêmeas, do ribeirão Boa Esperança, Estado de São Paulo. Um espécime acha-se guardado, sob n. ${ }^{\circ} 438$, na coleção do Departamento de Zoologia da Universidade de S. Paulo.

Hospedadores: Lambarís do rabo amarelo (Tetragonopterus a u reus) e lambarís do rabo vermelho (Tetragonopterus ruti! us).

Descrição: Corpo deprimido e alongado (Fig. I e 2), três vezes mais comprido do que largo, em cujo cefalotorax não existem sinais evidentes de segmentação. No animal vivo, nota-se um envoltório constituido por uma 
cuticula branca, fina e muito resistente que, nos exemplares mais jovens. é muito evidente e que adére completamente ao corpo do Crustáceo pela ação dos fixadores. E' totalmente desprovido de espinhos ou apêndices de fixação.

A carapaça é constituida por dois lóbulos laterais divergentes, em forma de asas que se originam no cefalotorax e descem até além do terço superior dos lóbulos abdominais; terminam em ponta e raramente excedem o comprimento dêsses orgãos. Essas expansões lanceoladas são mais alargadas na porção anterior, constatando-se nélas a existência de numerosos canalículos hepáticos, muito evidentes, que dão a impressão de ramos irregulares, abundantemente distribuidos, como se fossem inervaturas espalhadas sôbre o limbo de uma folha lanceolada (Fig. I).

Cabeça de tamanho medíocre, unida ao cefalotorax, com uma reintrância ou séla na porção média anterior de modo a formar dois lóbulos laterais arredondados, sôbre os quais se acham localisados dois olhos grandes, bem visíveis, tanto do plano dorsal como do ventral (Fig. 3).

Antênulas e antenas (Fig. 4) são situaldas na porção inferior da cabeça, na região compreendida entre os orgãos visuais e a plataforma cral. São apêndices diminutos e rudimentares. As antênulas não são articuladas e na sua base existe um corpo arredondado. Da porção média, parte uma espícula forte, réta, com a ponta aguda voltada para cima. Na extremidade. figuram cinco ou seis prolongamentos apicais e dois dentes curtos inferiores. As antenas são quasi do mesmo tamanho ou ligeiramente mais longas do que as antênulas e são constituidas por uma porção basal de forma globular, armada de quatro acúleos recurvados e dois rétos. A porção distal cilindrica é dividida em dois artículos mal definidos, existindo na região apical cinco ou seis acúleos e dois dentes curtos inferiormente situados.

Ambos os orgãos ficam presos à face ventral da carapaça por meio de um pedúnculo carnoso; acham-se situados entre o bordo anterior da cabeça e a região oral, ficando meio encobertos pelos bordos superiores dos discos adesivos.

As chamadas ventosas são grandes, oblongas, pedunculadas, quasi unidas e situadas na parte anterior do cefalotorax. Originam-se das maxilas e acham-se situadas de cada lado do cône bucal. Como acontece com as ventosas dos demais Arguloida, êsses orgãos são providos de um exosqueleto quitínico, sustentado pelas costelas dispostas horizontalmente e em duas camadas paralelas, ao longo dos bordos dos discos (Fig. 5).

As costelas diferem, destarte, dos elementos correspondentes do gênerc Argulus, em que essas colunas de sustentação se encontram sempre verticalmente dispostas. 
A bôca, situáda entre os discos adesivos, na região média posterior ventral do cefalotórax, fica parcialmente encoberta pelos bordos dêsses discos, formando aí um cône proeminente. E' constituida por um pedúncuio em forma de cilindro algo bojudo e susceptivel de se protraír (Fig. 7). Na sua extremidade anterior, figura um disco arredondado (Fig. 6), côncavo, flexivel, de bordos irregulares e da forma de um prato. No centro dêsse disco há uma corôa carnuda, à semelhança de lábios, que serve de borda a um cálice provido de paredes pregueadas, de aspéto crecentiforme (mandíbulas). O dito cálice dá início a uma cavidade afunilada a que se segue um esófago muscular.

Os maxilípodos são curtos e robustos, formados de cinco artículos (Figs. 8 e 9). O primeiro artículo é representado por uma prega rugosa, mal definida, porém, bem evidente. O terceiro artículo é provido de duas calosidades, uma lisa e núa, outra da forma dum rim e coberta por pequenas papilas hemisféricas ou semielípticas. Notam-se, nessas papilas, dentículos ou prolongamentos de fixação, em forma de pente. As papilas assemeIham-se muito às que se encontram nos maxilípodos posteriores de $\mathrm{Arg}$ ulus americanus e de A. versicolor.

O quarto artículo do maxilípodo é entumescido e provido de papilas na sua porção superior. $O$ artículo terminal é digitiforme, com dentículos no bordo superior, pequenos e encurvados, além de dois dentes maiores, grossos e ponteagudos que se acham localisaldos na porção latero-distal.

O torax é mais longo do que largo. Nas fêmeas, observam-se facilmente, por transparência, carreiras laterais de óvulos pequenos, de contorno irregular que medem cerca de $290 \mu \times 275 \mu$ (Fig. 12), com vitelo nutritivo abundante. No torax encontram-se ainda fileiras irregulares de pequenas manchas de côr castanho-escura ou totalmente negras, pigmentação essa que se estende da porção dorsal até a região latero-inferior ou ventral. Em toda a extensão média dorsal, há um espaço completamente idesprovido dessas manchas.

Os apêndices torácicos (Figs. 10 e II), em número de quatro pares, acham-se situados ao longo e de cada lado da região torácica. São representados por uma pre-coxa, uma coxa e uma basis. Os ramos dêsses apêndices, constituidos pela coxa e pre-coxa, são sempre mais curtos do que a basis. Da pre-coxa partem dois ramos terminais: o exopodito e 0 endopodito, munidos de raras espículas, ligeiramente encurvadas e muito pouco cerdósas. No primeiro par, o endopodito é um tanto mais curto do que o exopodito. Nos segundo, terceiro e quarto pares os ramos tambêm não teem o mesmo comprimento, sendo o endopodito algo mais longo. A basis do último par é mais idesenvolvida do que a dos demais, néla figurando uma protuberância ou lóbulo natatório, na porção infero-posterior. 
O abdomen é formado por dois prolongamentos terminais longos, de forma lanceolada, que lembram os do gênero Dolops. Sôbre a superfície externa dêsses orgãos existem numerósos e minúsculos pêlos tácteis. No ângulo formado pela junção dos ramos abdominais, logo após a porçãc posterior do torax, acham-se localisados os orgãos sexuais, bem evidentes e de um colorido alaranjaldo escuro. Não se constata a presença de ramos caudais.

Os animais vivos teem uma côr amarela brilhante ou aproximada ao âmbar, existindo exemplares que possuem tonalidades bastante carregadas. Em geral, os espécimes jovens são quasi brancos, nêles evidenciando-se, com muita nitidez, os dois pontinhos negros dos olhos e os círculos ovalados dos orgãos sexuais.

\section{Medidas}

Postas em confronto as medidas dos exemplares de Calman, de Moreira e os meus, verifica-se que ha uma concordância quasi que perfeita entre as que foram obtidas por Moreira e por mim, ao passo que o mesmo já não acontece com as de Calman. Na própria estampa que o criador do gênero Dipteropeltis apresenta, nota-se no seu espécime um comprimento exagerado dos lóbulos laterais do cefalotorax.

\begin{tabular}{|c|c|c|c|}
\hline \multicolumn{4}{|c|}{ MEDIDAS EM MILIMETROS } \\
\hline & Calman & Moreira & $\begin{array}{c}\text { Material } \\
\text { de Boa } \\
\text { Esperança }\end{array}$ \\
\hline 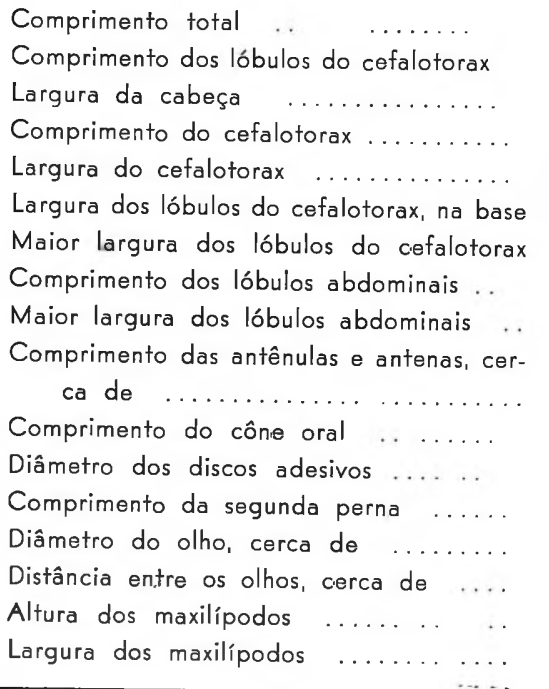 & $\begin{array}{l}20 \\
26 \\
2,5 \\
8 \\
2,5 \\
1,8 \\
4,8 \\
6,8 \\
1,3 \\
0,13 \\
0,5 \\
1,1 \\
1,8 \\
0,1 \\
0,45 \\
\end{array}$ & $\begin{array}{l}11-15 \\
9-13 \\
- \\
6-8,5 \\
2,5-3 \\
-- \\
4-6 \\
- \\
\square \\
- \\
- \\
-\end{array}$ & $\begin{array}{c}11,5-15 \\
6-13 \\
2,5-3 \\
6-8,5 \\
2,5-3 \\
1,5-1,8 \\
4,5-4,8 \\
4-6,5 \\
1,3-1,5 \\
- \\
551 \times 435 \\
- \\
1,1-1,3 \\
0,40-0,60\end{array}$ \\
\hline
\end{tabular}




\section{Comentário}

Em trabalho anterior (Paiva Carvalho 1939, p. 110) já tive ocasião de lembrar que os Branchiura foram inicialmente, por alguns autores, incluidos nos Phyllopoda, e, realmente, apresenta a organisação interna certos traços conhecidos dos Euphyllopoda. Atualmente os Carcinólogos ou seguem a G. O. Sars, incluindo os Branchiura, como sub-ordem Arguloida, na ordem dos Copepoda (Wilson 1932, p. 10-11), ou consideram o grupo como ordem especial, aplicando o nome de Branchiura (Brehm 1927. p. 497). Como a entidade abrange apenas ca. de 60 espécies talvez possa parecer inconveniente dar-lhe gráo de ordem especial, favorecendo, além disso, as extremidardes larvais e a ocorrência da espermatoteca (receptáculo seminal), a incorporação dos Arguloida nos Copepoda. Por outro lado, constituem os olhos compostos e o cefalotorax escutiformemente alargado caracteres incompatíveis com a diagnose geral dos Copepoda. Os quatro pares de extremidades natatórias da região torácica lembram, com os seus dois ramos estreitos mais os cirrípodos dos Cirriperdia do que os pés remadores, aos quais os Copepoda devem o seu nome. E' verdade, que o termo "Branchiura" não deve ser aplicado no sentido duma respiração efetuada unicamente pelas folhas branquióides abdominais, visto participar a superfície inteira do animal na oxigenisação do líquido do corpo (Spandl 1926, p. 81).

Os Branchiura ou Arguloida conteem, atualmente, os gêneros seguintes: Argulus O. F Müller 1785, Dolops Audouin $1837(=$ Gyropeltis Heller 1857), Chonopeltis Thiele 1901 e Dipteropeltis Calman 1912 (= Tala us Moreira 1913; Moreiriella Mello-Leitão 1913). Nos três primeiros gêneros é a carapaça aproximadamente orbicular e ramos caudais são presentes, no último gênero é a carapaça alongada e os ramos caudais faltam. Os Branchiura são predominantemente límnicos, ocorrendo, porém, algumas espécies do gênero Argu!us, tambêm na água salobra e salgada. Os representantes dos gêneros Dolops e Dipteropeltis só foram, até agora, encontrados nágua doce, sendo Dipteropeltis, ao que parece, peculiar aos sistemas fluviais do Paraná e Paraguái.

O estudo dêsses ecto-parasitos torna-se indispensavel, dada a importância econômica de que se revestem, pois, as suas depredações podem causar prejuizos de certo vulto nos cardumes de peixes mantidos, sobretudo, em cativeiro. Meehean (1940, p. 459), referindo-se particularmente ao gênero Argulus, diz que lagôas e lagos têm sido despovoados em consequências dos seus ataques. Estudando as suas particularidades fisiológicas, Herter (1927) nos dá uma idéia da sua agressividade e Guberlet (1928, p. 9) aponta a sua capacidade de resistência. 
A espécie atual, Dipteropeltis hirundo Calm. foi, até agora, verificada como ecto-parasita dos douralos, piranhas e lambarís. Ao que se me afigura, parece não ser das mais nocivas, porque não ocorre em tão grande quantidade como, às vezes, acontece com as espécies dos gêneros Argulus e Dolops. Em oposição a certos lsopoda, sobretudo os da família Cymothoidae, a que o vulgo costuma chamar de "piolho de peixe" os Branchiura, talvez por causa da sua raridalde e relativa pequenez, ainda: não teem atraido a atenção dos nossos pescadores.

\section{Abstract}

The present material that serves as a base for the re-description of Dipteropeltis hirundo Calm. consists of four females found on Tetragonopterus aureus e T. rutilus in a small river in the state of S. Paulo, tributary to the river Parana.

The original material of Calman (1912) came from the river Paraguay (Corumba) and Moreira's specimens (1913; 1913a) had been collected in the same river.

Dipteropeltis hirundo Caim. includes, after Moreira (1915). Talaus ribeiroi (later on Moreiriella ribeiroil), but this last paper has been overlooked by Wilson (1932) who mentions both genera, Dipteropeltis Calman and Talaus Moreira as valid ones.

As Dipteropeltis hirundo does not seem to occur in so great a number as the species of Argulus and Dolops sometimes do, the parasite cannot be regarded as very noxious to the fishes.

\section{Literatura}

Brehm, V. 1927, 4. Ordnung der Crustacea Entomostraca: Branchiura. Kükenthal \& Krumbach, Handb. Zool. v. 3, 1. metade, p. 497-502. Berlin \& Leipzig (Walter de Gruyter \& Co.l.

Calman, W. T. 1912, On Dipteropeltis, a new genus of Crustacean Order Branchiura. Proc. Zool. Soc. London, p. 763-766, pl. 84. London.

Guberlet, J. E. 1928, Notes on a species of Argulus from gold-fish. Univ. Washington Publ. v. 2, n.ं 3, p. 3l-42. pl. 1-11. Washington.

Herter, K. 1937 Reizphysiologische Untersuchungen an der Karpfenlaus etc., Ztschr. vergl. Physiol. v. 5, fasc. 2, p. 283-370. Berlin.

Meehean, O. L. 1940, A review of the parasitic Crustacea of the genus Argulus in the collections of the U. S. Nat. Museum. Proc. U. S. Nat. Museum, v. 88, p. 459-522. Washington, D. C. 
Moreira, C. 1913, Crustacés du Brésil. Mém. Soc. Zool. France v. 25, p. 145-154 t. 3-4 Paris. - 1913a, Crustáceos. Com. Linhas Telegráficas Estrat. Mato-Grosso ao Amazonas. An. n.' 5, Hist. Nat. Zoologia, p. II, t. 3-4. Rio de Janeiro.

- 1915, Les antennes du Dipteropeltis hirundo Calman (Talaus Ribeiroi Moreira). Crust. Argulidae. Bull. Soc. Ent. France, p. 120 f. 1-2. Paris.

Neave, S. A., 1939-1940, Nomenclator Zoologicus, v. 1-4. London.

Paiva Carvalho, J. 1939, Sôbre dois parasitos do gênero Dolops, encontrados em peixes de agua dôce. Rev. Ind. Animal, nova série, v. 2, n. 4 , p. 109-116. S. Paulo.

Spandl, H. 1926, Branchiura, Kiemenschwänze. P Schulze, Biol. Tiere Deutschlands, fasc. 19. pars 15, p. 79-82. Berlin (Gebr. Borntraeger).

Wilson, C. B. 1932, The Copepods of the Woods Hole Region, Mass., U. S. Nat. Museum. Bull. n.* 158, 635 p., 41 t., 316 fig. Washington, D. C. 


\section{ESTAMPA XIX}

I - Dipteropeltis hirundo Calman - face dorsal, com os canalículos hepaticos representalos sôbre a expansão lateral direita.

2 - Dipteropeltis hirundo Calman - face ventral. 
JOÃO DE PAIVA CARVALHO - Sôbre Dipteropeltis hirundo Calman - ESTAMPA XIX

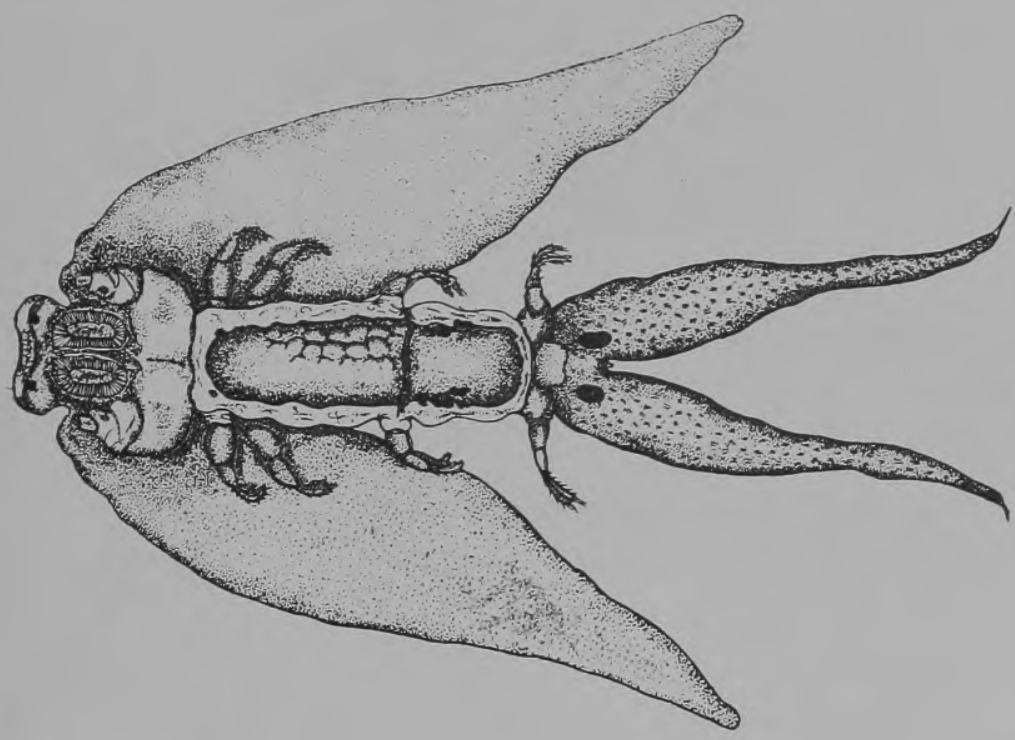

2.

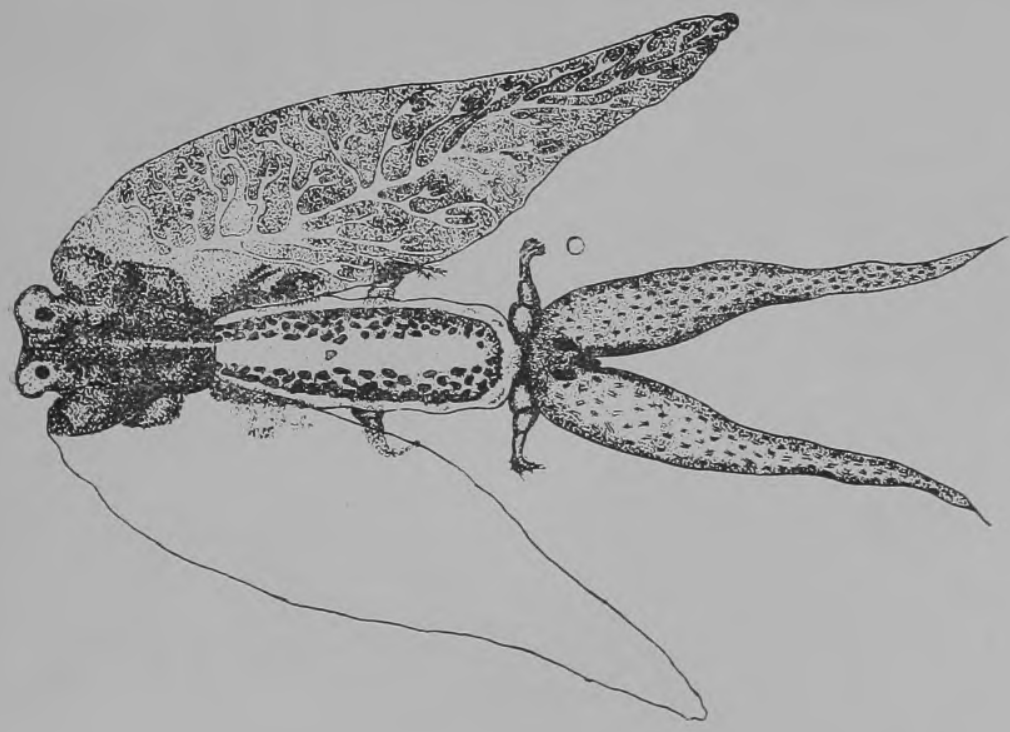




\section{ESTAMPA $X X$}

3 - Parte anterior da cabeça.

4 - Antênulas e antênas.

5 - Costelas de sustentação das ventosas.

6 - Rosêta da bôca.

7 - Plano lateral do cilindro bucal e rosêta da bôca.

8 - Maxilípodo, visto de frente.

9 - Maxilipodo, vista lateral.

10 - Terceira perna.

11 - Quarta perna.

12 - Ovo. 
JOÃO DE PAIVA CARVALHO - Sôbre Dipteropeltis hirundo Calman - ESTAMPA XX

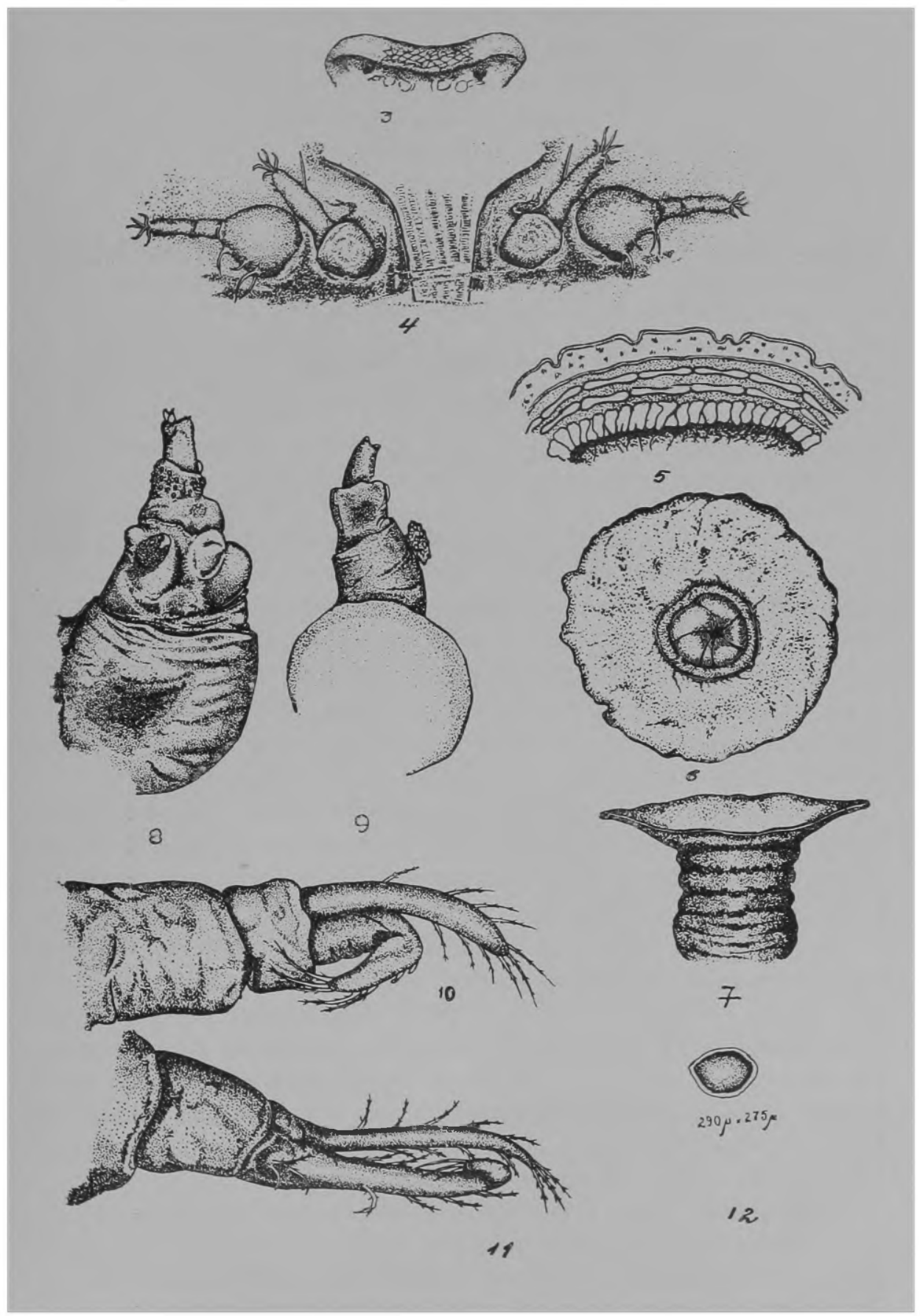

